\title{
Research Paper: Prediction of Marital Burnout Based on Feelings of Loneliness and Emotional Divorce in Infertile Women
}

\author{
Samaneh Zareh Zardini' ${ }^{1}$ (D), Alireza Jafari ${ }^{2 *}$ (D), Mohammad Ghamari ${ }^{3}$ (D) \\ 1. Department of Counseling, Faculty of Humanities, Science and Research Branch, Islamic Azad University, Tehran, Iran. \\ 2. Department of Psychology, Faculty of Humanities, Abhar Branch, Islamic Azad University, Abhar, Iran. \\ 3. Department of Counseling, Faculty of Humanities, Abhar Branch, Islamic Azad University, Abhar, Iran.
}

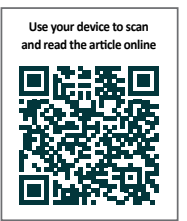

Citation Zareh Zardini S, Jafari AR, Ghamari M. Prediction of Marital Burnout Based on Feelings of Loneliness and Emotional Divorce in Infertile Women. Journal of Research \& Health. 2021; 11(5):323-332. http://dx.doi.org/10.32598/JRH.11.5.1854.1

http://dx.doi.org/10.32598/JRH.11.5.1854.1

\section{(i) (\$)}

Article info:

Received: 12 Dec 2020

Accepted: 14 Mar 2021

Publish: 01 Oct 2021

\section{Keywords:}

Marital conflict, Loneliness, Female infertility, Emotional divorce

\section{A B S T RACT}

Background: Infertility is one of the most painful experiences of life leads to marital burnout. Psychological, emotional, and social factors affect marital burnout of infertile women. This study was done to predict marital burnout based on feelings of loneliness and emotional divorce in infertile women.

Methods: The method of the research was descriptive-correlational. The participants were women (aged 25-45) referring to Ibn-e Sina Infertility Clinic in 2019 in Tehran. A sample of 175 participants was selected by convenience sampling and completed the Marital Burnout questionnaire, Feeling of Longlines questionnaire, and Emotional Divorce questionnaire. Data were analyzed by Pearson's correlation and multiple regression using SPSS v. 22.

Results: The results indicated that there was a significant and positive relationship between loneliness and its subscales (lack of intimacy and lack of social network) $(r=0.62)$ and also a positive and significant relationship was found between emotional divorce and its subscales (feeling of separation from each other, feeling of loneliness the need for a companion, boredom, and restlessness) and marital burnout $(\mathrm{r}=0.65)$. Also, feeling lonely and its subscales and emotional divorce and its subscales could predict the marital boredom of infertile women $(\mathrm{P}<0.01)$.

Conclusion: Feeling lonely and emotional divorce have a significant and positive relationship with marital boredom and can predict marital boredom in infertile women.

\footnotetext{
* Corresponding Author:

Alireza Jafari, PhD.

Address: Department of Psychologv, Faculty of Humanities, Abhar Branch, Islamic Azad University, Abhar, Iran.

Phone: +98 (912) 7131698

E-mail: samaneh.zaree69@gmail.com
} 


\section{Introduction}

$\mathbf{F}$

amily formation is the initiator of fertility and the source of production. Fertility is the most important life phenomenon for any couple. The general desire of people to have children is obvious and natural [1]. Infertility is a major gynecological problem and is the inability to conceive after one year of intercourse without using any method of contraception [2]. In 2015, the World Health Organization (WHO) cited infertility as a public health problem worldwide and reported that one of the four couples has been infertile in developing countries. Family formation is the initiation of fertility and the source of reproduction.

Infertility is a chronic problem that causes anxiety and stress in infertile people because it blocks the flow of family transformation to the next stages or at least poses a serious problem by creating an obstacle to achieving one of the main goals of marriage, namely reproduction and parenthood. In confronting this dilemma, infertile couples frequently experience a chronic monthly cycle of hope and frustration [3]. Infertility is considered a major gynecological problem and is defined as the inability to be pregnant after one year of intercourse without using any method of contraception [4].

Research has shown that infertility can disrupt interpersonal relationships and reduce self-esteem, social isolation, and mental health problems [5-7]. Infertility also leads to sexual dysfunction, depression, anxiety, frustration, guilt, and worthlessness [8-10]. One of the variables that are directly associated with infertility is loneliness. Feeling of loneliness is a kind of negative emotion that arises from the failure and weakness in interpersonal relationships and as a result, the person experiences feelings of sadness, emptiness, and lack of belonging.

The length of time a person is alone is not the main determinant of feelings of loneliness, but the threat of separation and the quality of communication with relatives play an important role in feelings of loneliness [11]. The feeling of loneliness is associated with decreased emotion, non-expression of interpersonal feelings, and psychological withdrawal so that the needs related to intimacy are not met and even if they are met to some extent, they remain dissatisfied. The feeling of loneliness indicates shortcomings and deficiencies in establishing emotional and social bonds. Feelings of loneliness arise when a person's contact and relationship with others are false so that a common emotional experience is not conceivable for this mutual relationship between the person and others and human being does not have a real and intimate relationship in the process of contact with others [12].
Given the very weak emotional basis and low intimacy in the marital relationship of infertile couples, it seems that the conditions for emotional divorce are provided. Another variable that can result from infertility is an emotional divorce in this situation, couples may continue to be together as a social group but the attraction and trust in each other are lost and each couple hurts the other because of feelings of sadness and despair [13].

Emotional divorce is considered as a kind of abnormality in the family system and symbolizes the existence of a problem in the relationship between husband and wife, which for reasons, such as not having children, material needs, negative attitude to formal divorce, lack of material and psychological support, family conflicts, fear of losing family and social status, fear of loneliness, fear of deteriorating social status, lack of decision-making pow$\mathrm{er}$, fear of a vague future, fear of being rejected by others or even getting used to living together make couples continue their marital life without having an emotional and sexual relationship and experience emotional divorce and loneliness, but do not talk about divorce [14].

The stress of infertility can weaken the foundation of the family and increase marital conflict, or even push them to divorce. On the other hand, after a while, the home environment without the presence of a child becomes boring for both husband and wife, and the silence and loneliness in the home become tedious for them. In most cases, infertile couples become impatient and this affects the relationship between them. Taken together, these problems can pave the way for reduced commitment and burnout in the marital relationship [15]. The most important aspect of life that is affected by infertility is the marital relationship, which causes marital burnout in couples by increasing the period of infertility [16]. After the emergence of burnout in marital relationships, distrust, humiliation, blame, inattention to each other, and emotional separation prevail and family members experience symptoms of reactive depression [17].

Shiri et al. found that marital burnout and distress tolerance have a direct effect on loneliness and the relationship between loneliness and the tendency to divorce is direct and significant. They also stated that marital burnout and distress tolerance against the tendency to divorce are significant due to the feelings of loneliness [18]. Heshmati et al. found that women and men who tend to stay in the present moment have a low level of lethargy and consequently, high marital satisfaction and vice versa [19]. 
Yamaguchi in his research showed that there is a negative and significant relationship between loneliness and marital commitment, meaning that the higher the loneliness of couples, the less commitment they have to their marital bond [20]. Larsen et al. and Burklund et al. showed that feelings of loneliness and social support can threaten the psychological well-being of infertile women by initiating distress and depression [21, 22].

Emotional divorce has consequences, such as depression, impatience, anxiety, worry, feelings of inferiority, and loss of self-confidence [23, 24]. Also, failure to meet the emotional needs of a man, inattention, communication problems, incorrect choice of spouse, sexual dissatisfaction, and lack of sense of responsibility are variables related to emotional divorce [25-27]. According to the WHO, infertility is a public health problem worldwide, and in a study conducted by this organization, $43 \%$ of women and $30.7 \%$ of men in the world suffer from infertility [28] and the infertility rate in Iran is $17 / 3 \%$. This puts a psychological and economic burden on the health system of the country as well as the family [29] Psychological factors of infertility are very important in the treatment of infertile couples. The issue of infertility is very important, especially in Iranian society, where families are of the expanded type to the extent that infertility is considered a crisis for many couples, and it is psychologically stressful and causes severe problems in the marital relationship. Furthermore, marital relationship is the most important factor that is influenced by sterility and is increased in sterility period leading to boredom in the relationship between couples [30].

Also, this leads to a defective cycle resulting in deep anxiety and stress; in these individuals who are under different treatments, including In Vitro Fertilization (IVF), Intrauterine Insemination (IUI), Intracytoplasmic Sperm Injection (ICSI), Pre-Implantation Genetic Diagnosis (PGD), and In vitro Maturation (IVM) anxiety and stress could spatter cortisol hormone, which causes unsuccessful treatment of sterility. Moreover, this can bring more complicity to a couple's relationship. Recognizing factors causing couple boredom, including the feeling of loneliness and emotional divorce is essential and can prevent posing major problems by proper interference. It is also noteworthy that because the researcher did not find an on all these variables in infertile women and this is the first study, the results can provide scientific and practical documentation for health providers; thus, it can be claimed that this study has appropriate innovations. Therefore, the present study was done to predict marital burnout based on feelings of loneliness and emotional divorce in infertile women.

\section{Methods}

The research method was descriptive-correlational. The statistical population consisted of women (aged 25-45 years) referring to Ibn-e Sina Infertility Center in Tehran in 2019 selected by available sampling method. A sample of 175 people was selected, which was selected based on the formula proposed by Tabajing and Fidel (2007).

After approving the research by the university and receiving the code of ethics from the university and submitting it to the management of Ibn-e Sina Clinic, explaining the objectives of the research and the necessity of conducting the research for the management of the clinic, as well as the fact that conducting such research does not interfere with the treatment process of the subjects, we received permission to conduct the research from the clinic management. Then, people eligible for the study were asked to participate in the study if possible.

The following measures were done to comply with ethical principles: 1. Description of research goals and methods, 2. Optional participation in research, 3. Confidentiality of information, 4. Possibility to participate in research.

The inclusion criteria were as follows: 1 . Starting cohabitation for at least one year, 2. Not getting pregnant after one year of intercourse without contraception, 3. Female infertility, 4 . The ages of 25 to 45 years, 5. Having at least a high school diploma.

Infertile women with a history of divorce, having marital problems other than infertility, and infertile women with mental disorders or addiction were excluded.

Since the research was descriptive and correlational, the only criterion for leaving the research was that when conducting the research, if they wished, they could avoid completing the questions in any way possible.

Then, the collected data were analyzed using SPSS v. 22 statistical software by descriptive (frequency, percentage, mean, and standard deviation) and inferential statistics of Kolmogorov-Smirnov test (for normal data), Pearson correlation coefficient, and multivariate regression.

\section{Research tools}

Pines Couple Burnout Measure (CBM): This scale is a self-measuring tool designed by Pines to measure marital burnout among couples. The scale has 21 items, of which 17 items include negative phrases of fatigue, inconvenience, and worthlessness, and 4 items include 
positive phrases of being happy and energetic. Items are scored on a 7-point Likert scale from never (score 1) to always (score 7). First, the scores of items 1, 2, 4, 5, 7, $8,9,10,11,12,13,14,15,16,17,18$, and 21 are added together and then, the scores of items 3, 6, 19, and 20 are summed and the obtained number is subtracted from 32 . Then, the scores obtained from the first and second stages are added together and divided by 21 . The obtained number indicates the degree of marital burnout and a higher number indicates a higher degree of marital burnout. Confirmatory factor analysis for the factor structure of the questionnaire confirmed its validity.

The reliability of this scale was 0.76 by retesting method in a one-month interval and the reliability coefficient was obtained between 0.91 and 0.93 using Cronbach's alpha method. Internal consistency between variables was in the range of 0.84 and 0.90 [31]. To evaluate the validity of this questionnaire, its correlation coefficient was calculated to be 0.40 using the Enrich Marital Satisfaction Questionnaire, which is significant and acceptable [32]. In the present study, the reliability of this scale was calculated to be 0.85 using Cronbach's alpha coefficient.

UCLA Loneliness Scale (Russell, 1996): This questionnaire was developed by Russell et al. It has 20 four-choice items, 10 negative sentences, and 10 positive sentences. In this questionnaire, the allocated scores are as follows: never $=1$, rarely $=2$, sometimes $=3$, and always $=4$. The score of items $1,5,6,9,10,15,16,19$, and 20 is inverse. The total score ranges from 20 to 80, and a higher score indicates the greater feeling of loneliness; and it has 2 subscales: lack of intimacy and lack of social network. The reliability of this instrument for the new version was 0.87 and was also reported equal to 0.89 by Russell through the retesting method [33]. In Iran, Hojati et al. calculated its reliability to be 0.89 through Cronbach's alpha method [34]. In the present study, the reliability of this scale was found to be 0.85 using Cronbach's alpha coefficient.

Gottman Emotional Divorce Scale (EDS): A 24-item Gottman Questionnaire was used to measure the subjects' emotional divorce. This tool has 24 items, which are scored as yes (1) and no (0). The total score of the instrument is obtained by summing the scores of the items, and the higher the score of the subject, the more likely is an emotional divorce. It has four subscales, including the feeling of separation from each other, feeling of loneliness, the need for a companion, and boredom and restlessness. After collecting the answers, if the number of positive answers is equal to 8 or higher, it means that the person's marital life is subjected to separation and signs of emotional divorce are evident. The structural validity of the questionnaire was approved using the factor analysis method and reported equal to 0.95 by Cronbach's alpha method [35]. The reliability of this questionnaire was reported to be 0.93 in the study by Momeni and Azadifard through Cronbach's alpha [24]. In the present study, the reliability of this scale was found to be 0.89 by Cronbach's alpha coefficient.

\section{Results}

Participants in the study were 175 infertile women and $29.14 \%$ (51 people) of them had started their marital life for six years and more, 64\% (112 people) for 3-5 years, and $6.85 \%$ (12 people) for 1-2 year(s). In terms of education level, $41.14 \%$ (72 people) had a diploma and lower, $6.28 \%$ (11 people) had an associate degree, $35.42 \%$ (62 people) had a bachelor's degree, and 14.28\% (25 people) had a master's degree. In terms of socio-economic classes, $27.42 \%$ (48 people) were at high, 50.85\% (89 people) were at average, and $21.71 \%$ (38 people) were at a low level. The mean participants' age was $34 \pm 3.83$ years. Among infertile women, $74 \%(n=130)$ had no history of infertility in their family and $25.71 \%(n=45)$ had a history of infertility in their family.

According to the results of Table 1, there was a positive and significant correlation between marital burnout and emotional divorce and its subscales, including separation, feeling of loneliness and isolation, need for a companion, feeling of loneliness, and its subscales of lack of intimate relationships, and lack of social network.

The results of Table 2 showed that the assumptions of data normality and collinearity of predictor variables were valid. To determine the share of emotional divorce variables and its subscales, including separation, feeling of loneliness and isolation, the need for a companion, feeling of boredom, and feeling of loneliness and its subscales, lack of intimate relationships, and lack of social network in predicting marital burnout of infertile women, the multivariate regression analysis was used simultaneously.

The results of Table 3 showed that the correlation coefficient between the dimensions of loneliness and marital burnout in infertile women was 0.62 and was significant at the level of 0.01 and using regression coefficients for the lack of an intimate relationship $(\mathrm{P}<0.01, \beta=0.207)$, lack of social network $(\mathrm{P}<0.01, \beta=0.152)$ and feeling of loneliness $(\mathrm{P}<0.01, \beta=0.361)$ can predict marital burnout in infertile women. 
Table 1. Mean $\pm S D$ and Pearson correlation coefficients of the research variables

\begin{tabular}{|c|c|c|c|c|c|c|c|c|c|c|}
\hline Variables & Mean \pm SD & 1 & 2 & 3 & 4 & 5 & 6 & 7 & 8 & 9 \\
\hline $\begin{array}{l}\text { 1. Separation from each } \\
\text { other }\end{array}$ & $4.67 \pm 1.45$ & 1 & & & & & & & & \\
\hline 2. Feeling of loneliness & $4.45 \pm 1.13$ & $0.26^{* *}$ & 1 & & & & & & & \\
\hline $\begin{array}{l}\text { 3. The need for a com- } \\
\text { panion }\end{array}$ & $4.78 \pm 1.09$ & $0.28^{* *}$ & $0.31^{* *}$ & 1 & & & & & & \\
\hline 4. Boredom & $5.23 \pm 1.34$ & $0.29^{* *}$ & $0.25^{* *}$ & $0.40^{* *}$ & 1 & & & & & \\
\hline $\begin{array}{l}\text { 5. The total score of the } \\
\text { emotional divorce }\end{array}$ & $15.96 \pm 3.87$ & $0.61^{* *}$ & $0.70^{* *}$ & $0.71^{* *}$ & $0.58^{* *}$ & 1 & & & & \\
\hline $\begin{array}{l}\text { 6. Lack of intimate relation- } \\
\text { ships }\end{array}$ & $46.12 \pm 5.65$ & $0.52^{* *}$ & $0.61^{* *}$ & $0.62^{* *}$ & $0.51^{* *}$ & $0.62^{* *}$ & 1 & & & \\
\hline 7. Lack of social network & $39.34 \pm 5.02$ & $0.56^{* *}$ & $0.49^{* *}$ & $0.61^{* *}$ & $0.54^{* *}$ & $0.63^{* *}$ & $0.45^{* *}$ & 1 & & \\
\hline 8. Restlessness & $68.03 \pm 11.19$ & $0.58^{* *}$ & $0.53^{* *}$ & $0.65^{* *}$ & $0.57^{* *}$ & $0.60^{* *}$ & $0.77^{* *}$ & $0.69^{* *}$ & 1 & \\
\hline 9. Marital burnout & $83.25 \pm 9.63$ & $0.66^{* *}$ & $0.81^{* *}$ & $0.79^{* *}$ & $0.64^{* *}$ & $0.75^{* *}$ & $0.73^{* *}$ & $0.58^{* *}$ & $0.80^{* *}$ & 1 \\
\hline
\end{tabular}

**P $<0.05$

UPA

The results of Table 4 showed that the correlation coefficient between the dimensions of emotional divorce and marital burnout in infertile women was 0.65 and at the level of 0.01 , and using regression coefficients of separation and distance $(\mathrm{P}<0.01, \beta=0.271)$, the feeling loneliness and isolation $(\mathrm{P}<0.01, \beta=0.415)$, need for a companion $(\mathrm{P}<0.01, \beta=0.302)$, feeling bored $(\mathrm{P}<0.01$, $\beta=0.294)$, and emotional divorce $(\mathrm{P}<0.01, \beta=0.447)$ can predict marital burnout in infertile women.

\section{Discussion}

The aim of this study was to predict marital burnout based on the feeling of loneliness and emotional divorce in infertile women. The results showed that feeling of loneliness and its dimensions could positively and significantly predict marital burnout of infertile women. These results are consistent with the findings of previous research [36-41]. Feeling alone not only affected the quality of the married life of couples but can also lead to intensification of marital conflicts and boredom between couples.

The experience of infertility is associated with physical, psychological, and social stress that affects all aspects of a person's life, reducing marital intimacy and self-esteem, and increasing the fear of separation, divorce, rejection, isolation, and psychosomatic disorders [41] Karaca and Unsal also found that infertility has a negative

Table 2. Results of data normality and collinearity tests of predictor variables

\begin{tabular}{ccc}
\hline Variables & Kolmogorov and Smirnov & The Variance of the Inflation Factor \\
\hline $\begin{array}{c}\text { Separation from each other } \\
\text { Feeling of loneliness }\end{array}$ & 0.413 & 1.24 \\
\hline The need for a companion & 0.526 & 1.33 \\
\hline Boredom & 0.380 & 1.54 \\
\hline The total score of the emotional divorce & 0.543 & 1.42 \\
\hline Lack of intimate relationships & 0.652 & 1.23 \\
\hline Lack of social network & 0.231 & 1.46 \\
\hline Restlessness & 0.563 & 0.127 \\
\hline
\end{tabular}


Table 3. Results of multivariate regression analysis for the feeling of loneliness and marital burnout in infertile women

\begin{tabular}{|c|c|c|c|c|c|c|c|c|}
\hline \multirow[t]{2}{*}{ Predictive Variables } & \multirow[t]{2}{*}{$\mathbf{R}$} & \multirow[t]{2}{*}{$\mathbf{R}^{2}$} & \multirow[t]{2}{*}{$\mathbf{F}$} & \multicolumn{2}{|c|}{$\begin{array}{l}\text { Non-Standard } \\
\text { Coefficients }\end{array}$} & \multirow{2}{*}{$\begin{array}{c}\begin{array}{c}\text { Standard } \\
\text { Coefficients }\end{array} \\
\text { B }\end{array}$} & \multirow[t]{2}{*}{$\mathbf{T}$} & \multirow[t]{2}{*}{ Sig. } \\
\hline & & & & B & SD & & & \\
\hline Constant & & & & 85.61 & 0.713 & - & 21.651 & 0.001 \\
\hline Lack of an intimate relationship & 0.62 & 0.38 & $51.69^{* *}$ & 0.612 & 1.410 & 0.207 & 6.514 & 0.005 \\
\hline Lack of social network & & & & 0.558 & 0.399 & 0.153 & 2.338 & 0.003 \\
\hline Feeling of loneliness & & & & 0.761 & 0.428 & 0.361 & 7.742 & 0.001 \\
\hline
\end{tabular}

**P<0.01

effect on people's self-concept and opinion [42]. Women used psychological coping styles to overcome stress and avoid societal pressures, and also they used traditional methods of fertility that created a greater feeling of isolation and loneliness. Infertile women suffer from various psychosocial problems due to infertility and to deal with it, they use more emotional coping methods [42].

Tsapelas et al. assessed couples with the marriage age of 9 years and showed that marital burnout is directly or indirectly affected by events and problems related to the marital relationship that can prevent the satisfaction of psychological and emotional needs of spouses [43]. Items, such as not having children, lack of intimacy, and boredom provide the background for the formation of cold emotional relationships that lead to low marital satisfaction, marital burnout, and feeling of loneliness [43]. The findings can be explained as follows: because sexual satisfaction for spouses is one of the most important determinants of marital satisfaction, infertility affects sexual satisfaction and marital burnout occurs leading to feelings of loneliness and isolation for infertile women.
On the other hand, according to Weiss's theory, loneliness due to social isolation or social deprivation prepares a person for mood disorders and other emotional and behavioral injuries in personal and marital life. According to this model, when a couple feels lonely with a couple in the form of social isolation, the person does not move towards interaction with his spouse and may block all paths of interaction. Eventually, the couple's relationship conflicts if one or both couples have a feeling of loneliness based on emotional isolation. In the second type of loneliness, people avoid expressing their feelings and emotions and feel that they cannot share their emotions with others. Whether the couples share their emotions or the other person does not understand these emotions, this causes the couple to separate from each other and marital conflicts [44].

Also, it can be explained that marital boredom is caused by some irrational expectations, inattention of couples to each other's needs, and inability to manage emotions and has physical, and psychological, and emotional symptoms. People with this syndrome feel ruined in life and have a pessimistic view of their spouse and feel that they cannot change the situation. For this reason, they decide

Table 4. Results of multivariate regression analysis of the effect of emotional divorce on marital burnout in infertile women

\begin{tabular}{|c|c|c|c|c|c|c|c|c|}
\hline \multirow[t]{2}{*}{ Predictive Variables } & \multirow[t]{2}{*}{$\mathbf{R}$} & \multirow[t]{2}{*}{$\mathbf{R}^{2}$} & \multirow[t]{2}{*}{$\mathbf{F}$} & \multicolumn{2}{|c|}{$\begin{array}{l}\text { Non-Standard } \\
\text { Coefficients }\end{array}$} & \multirow{2}{*}{$\begin{array}{c}\begin{array}{c}\text { Standard } \\
\text { Coefficients }\end{array} \\
\text { B }\end{array}$} & \multirow[t]{2}{*}{$\mathbf{T}$} & \multirow[t]{2}{*}{ Sig. } \\
\hline & & & & B & Sd & & & \\
\hline Constant & & & & 92.54 & 0.674 & - & 16.03 & 0.005 \\
\hline Separation & & & & 0.632 & 1.566 & 0.271 & 4.56 & 0.001 \\
\hline Feeling of loneliness & 0.65 & 0.42 & $63.04^{* *}$ & 0.418 & 2.169 & 0.415 & 2.44 & 0.003 \\
\hline The need for a companion & & & & 0.561 & 1.175 & 0.302 & 5.35 & 0.006 \\
\hline Boredom & & & & 0.712 & 1.805 & 0.294 & 7.11 & 0.005 \\
\hline Emotional divorce & & & & 0.761 & 1.352 & 0.427 & 9.34 & 0.001 \\
\hline
\end{tabular}

**P $<0.01 ; * * \mathrm{P}<0.05$ 
to spend the little energy that is left for them, and because they do not try to change the situation, the distance between them is increased, and in the end, this situation leads to marital dissatisfaction, conflict, and boredom. Another finding of our study was that emotional divorce and its dimensions could predict marital boredom of infertile women. This finding is consistent with the results of previous studies [45-52]. When a marriage fails to prevent loneliness in the person, anger, bitterness, and emotional rejection occur, which eventually leads to the tendency of people to separate and divorce.

The inherent importance of motherhood for women has made infertility a serious threat to pleasurable emotions and feelings, and as a result, to the marital relationship. Infertility is one of the main causes of dissatisfaction and incompatibility of infertile couples and gradually causes stress, the feeling of frustration, and social withdrawal [53]. Because infertile women have unpleasant thoughts and feelings about the past and the future and the story of their life, which is a sort of being sacrificed, they thus lose "being in the present" and this causes strengthening the attitude of infertility and reducing the psychological and emotional relationship with the spouse and consequently, reducing the quality of marital life.

Having a negative attitude towards infertility and not having children exacerbates the problem of women's infertility and reduces their mental health [54]. Therefore, given the negative and unpleasant consequences of infertility in women, after a while, it creates a feeling of frustration and social withdrawal in them, which increases their feeling of loneliness. In addition, infertility leads to a decrease in the psychological and emotional relationship with the spouse, which creates the ground for emotional divorce. Accordingly, the occurrence of serious marital burnout in infertile women is affected by these two negative complications, namely loneliness and emotional divorce.

Marital boredom is a gradual decrease in emotional attachment to the spouse, which is accompanied by feelings of alienation, apathy, and indifference between couples and replacing negative emotions with positive emotions, and causes the loss of initial enthusiasm, emotional attachment, and commitment. Boredom is a kind of feeling of depression in cohabitation, while excitement facilitates the relationship between couples, and this in itself makes people closer to each other, which is the end product of these conditions to increase the level of satisfaction in the long run. This closeness between couples through well-known mechanisms, such as commitment, responding to the partner, trust, etc., increases the level of satisfaction of couples, and the important point is that couples through exciting activities and creating joy in their relationships will reduce the level of boredom and reciprocally, reduce the likelihood of any marital burnout and emotional divorce.

Marriage is the source of some of our deepest feelings and emotions, such as love, hate, anger, fear, sadness, and pleasure, and how much a couple can understand these strong emotions talk about them, and manage them plays a crucial role in their marital satisfaction and preventing emotional divorce. Expression of emotions plays a major role in the happiness and continuity of married life, and happy couples constantly express reactions, such as love and affection for each other and make appropriate jokes in their interactions with each other. People with high emotional expression are more likely to be able to effectively resolve problems, distinguish differences through precise and subtle emotional conversations, and use problemsolving skills to increase intimacy in marital relationships and prevent them from emotional divorce. When some people feel that their spouse is not available, respondent, and is critical instead, they mostly use emotional strategies that unintentionally increase tension in their relationship and make the union between them weaker.

These strategies include either blaming anxiously or showing cold shoulder. When a spouse is not aware of his or her spouse's emotional response in crisis and is not sure that she or he is available enough to respond emotionally, he or she starts to feel incertitude. This feeling causes that every spouse feels that is alone to encounter stress and anxiety in life. Moreover, this could lead to an emotional divorce between the couples and eventually, result in boredom and divorce.

\section{Conclusion}

According to the research findings, it can be concluded that feelings of loneliness and emotional divorce are complications of infertility in women that play a role in predicting marital burnout in infertile women. Because infertile women often make many unsuccessful attempts to conceive, they experience a great deal of helplessness and failure to achieve a spiritual need, that is, to have children, which after a while, leads to a feeling of isolation and inner loneliness. Also, the desire for sexual relations and psychological and emotional interactions that are the basis and necessity of an effective marital relationship decreases in infertile women, which creates the ground for the formation of indifference and emotional divorce in the marital relationship. Thus, the negative consequences of infertility, which lead to the feeling 
of loneliness and emotional divorce in infertile women, create a negative attitude towards not having children for them and prevent them from experiencing an effective marital relationship in couples, and make them burnout and bored of married life. It was not possible to compare infertile women with infertile men considering the studied variables. Using of available sampling method which could be associated with inherent error was not possible which disrupted the generalization of findings.

\section{Ethical Considerations}

\section{Compliance with ethical guidelines}

This study was approved by the Ethics Committee of the Islamic Azad University, Science and Research Branch (Code: 11891558).

\section{Funding}

This research did not receive any grant from funding agencies in the public, commercial, or non-profit sectors.

\section{Authors' contributions}

Conceptualization, methodology, software, validation, formal analysis, investigation, resources, data curation, writing - original draft preparation, and funding acquisition: Samaneh Zare Zardini; Writing - review \& editing, visualization, supervision, project : Alireza Jafari and Mohammad Ghamar; Administration: Alireza Jafari.

\section{Conflict of interest}

The authors declared no conflict of interest.

\section{Acknowledgments}

We appreciate the worthy cooperation of the officials of Ibn Sina Infertility Clinic in Tehran and all infertile women participating in the study.

\section{References}

[1] Farrokh-Eslamlou H, Vahabzadeh Z, Moeini R, Moghaddam Tabrizi F. [Pre-marriage couples` fertility attitude following recent childbearing persuasive policies in Iran (Persian)]. J Nurse Midwifery. 2014; 11(10):836-46. http:// unmf.umsu.ac.ir/article-1-1649-fa.html

[2] Shahsavari Isfahani S, Morshed Behbahani B, Beigizadeh S, Sobhanian S. [Epidemiological factors associated with infertility in infertile couples referred to clinic of Peymaniyeh Hospital in Jahrom in years 1999-2009]. J Sci Health 2010; 5(89):51-60. http://knh.shmu.ac.ir/index.php/site/ article/view/984

[3] Peterson BD, Newton CR, Rosen KH, Shulman RS. Coping processes of couples experiencing infertility. Fam Relat 2006; 55(2):227-39. [DOI:10.1111/j.1741-3729.2006.00372.x]

[4] Azizi A. Regulation of emotional, marital satisfaction and marital lifestyle of fertile and infertile. Rev Eur Stud. 2018 10(1):14-24. [DOI:10.5539/res.v10n1p14]

[5] Wischmann T, Korge K, Scherg H, Strowitzki T, Verres R. A 10-year follow-up study of psychosocial factors affecting couples after infertility treatment. Hum Reprod. 2012; 27(11):3226-32. [DOI:10.1093/humrep/des293] [PMID]

[6] Galhardo A, Pinto-Gouveia J, Cunha M, Matos M. The impact of shame and self-judgment on psychopathology in infertile patients. Hum Reprod. 2011; 26(9):2408-14. [DOI:10.1093/humrep/der209] [PMID]

[7] Bhatti LI, Fikree FF, Khan A. The quest of infertile women in squatter settlements of Karachi, Pakistan: A qualitative study. Soc Sci Med. 1999; 49(5):637-49. [DOI:10.1016/S02779536(99)00142-2] [PMID]

[8] Chachamovich JR, Chachamovich E, Ezer H, Fleck MP Knauth D, Pass EP. Investigating quality of life and healthrelated quality of life in infertility: A systematic review. Psychosom Obstet Gynaecol. 2010; 31(2):101-10. [DOI:10.31 09/0167482X.2010.481337] [PMID]

[9] Bokaie M, Simbar M, Yassini Ardekani SM, Alavi-Majad $\mathrm{H}$. [How infertility effects on sexual function of infertile couples? (Persian)]. Nurs Midwifery J. 2014; 25(91):47-56. https://www.sid.ir/fa/journal/ViewPaper.aspx?ID=271050

[10] Nelson CJ, Shindel AW, Naughton CK, Ohebshalom M, Mulhall JP. Prevalence and predictors of sexual problems, relationship stress, and depression in female partners of infertile couples. J Sex Med. 2008; 5(8):1907-14 [DOI:10.1111/ j.1743-6109.2008.00880.x] [PMID]

[11] Dasht Bozorgi Z. [Effectiveness of self- compassion therapy on loneliness and emotion regulation of damaged women from marital infidelity (Persian)]. Knowl Res Appl Psychol. 2017; 18(2):72-9. https://www.sid.ir/fa/journal/ ViewPaper.aspx?ID=346918

[12] Vanhalst J, Goossens L, Luyckx K, Scholte RHJ, Engels RCME. The development of loneliness from mid- to late adolescence: trajectory classes, personality traits, and psychosocial functioning. J Adolesc. 2016; 36(6):1305-12. [DOI:10.1016/j.adolescence.2012.04.002] [PMID]

[13] Gager CT, Yabiku ST, Linver MR. Conflict or divorce? Does parental conflict and/or divorce increase the likelihood of adult children's cohabiting and marital dissolution? Marriage Fam Rev. 2016; 52(3):1-18. [DOI:10.1080/0 1494929.2015.1095267]

[14] Yazdani A, Haghighatian M, Keshavarz H. [An analysis of quality of life among emotional divorced women (case study: Shahrekord) (Persian)]. Soc Cult Res J Rahbord. 2015; 2(6):159-85. [DOI:20.1001.1.22517081.1392.2.1.6.0] 
[15] Khodakarami N, Hashemi S, Seddigh S, Hamdiyeh M, Taheripanah R. [Life experience with infertility: A phenomenological study (Persian)]. J Reprod Infertil. 2010; 10(4):287-97. https:// www.jri.ir/article/397

[16] Tao P, Coates R, Maycock B. Investigating marital relationship in infertility: A systematic review of quantitative studies. J Reprod Infertil. 2012; 13(2):71-80. [PMID] [PMCID]

[17] Graff HJ, Christensen U, Poulsen I, Egerod I. Patient perspectives on navigating the field of traumatic brain injury rehabilitation: A qualitative thematic analysis. Disabil Rehabil. 2018; 40(8):926-34. [DOI:10.1080/09638288.2017.1280542] [PMID]

[18] Shiri T, Farahbakhsh K, Zolfaghri S. [Anticipation of divorce tendency based on marital Burnout and distress tolerance by the mediation of loneliness in female applicants for divorce (Persian)]. Couns Cult Psychother. 2020; 11(42):121-41. [DOI:10.22054/QCCPC.2020.43452.2164]

[19] Heshmati R, Gharadaghi A, Jafari E, Golizadegan M. [Prediction of marital burnout in couples seeking divorce with knowledge of demographic characteristics, mindfulness, and emotional resilience (Persian)]. Fam Couns Psychother. 2017; 1(23):1-22. [DOI:20.1001.1.22516654.1396.7.1.2.2]

[20] Yamaguchi M, Smith A, Ohtsubo Y. (2017). Loneliness predicts insensitivity to partner commitment. Pers Individ Dif. 2017 105:200-7. [DOI:10.1016/j.paid.2016.09.047]

[21] Larsen U, Hollos M, Obono O, Whitehouse B. Suffering infertility: The impact of infertility on women's life experiences in two Nigerian communities. J Biosoc Sci. 2010; 42(6):787-814. [DOI:10.1017/S0021932010000271] [PMID] [PMCID]

[22] Burklund LJ, Torre JB, Lieberman MD, Taylor SE, Craske MG Neural responses to social threat and predictors of cognitive behavioral therapy and acceptance and commitment therapy in social anxiety disorder. Psychiatry Res Neuroimaging. 2017; 261:52-64. [DOI:10.1016/j.pscychresns.2016.12.012] [PMID] [PMCID]

[23] Sahebihagh MH, Khorshidi Z, Barzanjeh Atri S, Asghari Jafarabadi M, Hassanzadeh Rad A. [The rate of emotional divorce and predictive factors in nursing staff in North of Iran (Persian)]. Int J Womens Health Reprod Sci. 2018; 6(2):174-80. [DOI:10.15296/ ijwhr.2018.29]

[24] Momeni K, Azadfard IS. [The relationship between sexual knowledge and attitude, and relational beliefs with emotional divorce (Persian)]. Fam Path Coin Enj. 2015; 1(2):34-45. [DOI:20 .1001.1.24234869.1394.1.2.4.5]

[25] Adedini SA, Somefun OD, Odimegwu CO, Chizomam Ntoimo LF. Union dissolution - divorce, separation, and widowhood in Sub-Saharan Africa: Trends, patterns, and determinants. In: Odimegwu CO, editor. Family Demography and Post-2015 Development Agenda in Africa. Cham: Springer Nature; 2019. p.127-45. [DOI:10.1007/978-3-030-14887-4_7]

[26] Cahn AND, Singer J. Review: Divorce American Style. Family Law Q. 2016; 50(1):139-49. https://www.jstor.org/stable/44155201

[27] Hashemi L, Homayuni H. Emotional divorce child's wellbeing. J Div Rem. 2017; 58(8):631-44. [DOI:10.1080/10502556.20 16.1160483]

[28] Afshani SA, Ghaem Mohammadi SMR, Khani P, Khosravi A. Role of resilience training on compromising of infertile couples' applicant for divorce: A cross-sectional study. Int J Reprod Biomed. 2020; 18(3):193-200. [DOI:10.18502/ijrm.v18i3.6717] [PMID] [PMCID]
[29] Hasanzadeh Lifshagard M, Tarkhan M, Taghizadeh ME. [Effectiveness of stress inoculation training on perceived stress in pregnant women with infertility (Persian)]. J Holist Nurs Midwifery. 2013; 23(2):27-34. http://hnmj.gums.ac.ir/ article-1-25-en.html

[30] Alizadeh S, Hadizadeh M, Ameri H. [Assessing the effects of infertility treatment drugs using clustering algorithms and data mining techniques (Persian)]. J Mazandaran Univ Med Sci. 2014; 24(114):26-35. http://jmums.mazums.ac.ir/article1-3945-en.html

[31] Pines AM. Couple burnout: Causes and cures. Abingdon: England, UK: Routledge; 1996. https://books.google.com/ books?id=3p41UVU1RxsC\&dq

[32] Naderi F, Eftekhari Z, Amolazadeh S. [The correlation among personality characteristics and intimate relationship with couple burnout in spouses of addict men in Ahvaz (Persian)]. J Sociol Psychol. 2009; 3(11):61-78. https://www.sid. ir/fa/journal/ViewPaper.aspx?ID=124229

[33] Russell DW. UCLA Loneliness Scale (Version 3): Reliability, validity, and factor structure. J Pers Assess. 1996; 66(1):2040. [DOI:10.1207/s15327752jpa6601_2] [PMID]

[34] Hojati H, Sharifnia SH, Hosseinalipour S, Akhondzadeh $\mathrm{G}$, Asayesh $\mathrm{H}$. [The effect of reminiscence on the amount of group self- esteem and life satisfaction of the elderly (Persian)]. J Urmia Nurse Midwifery Fac. 2011; 9(5):350-6. http:// unmf.umsu.ac.ir/article-1-607-fa.html

[35] Dzara K. Assessing the effect of marital sexuality on marital disruption. Soc Sci Res. 2010: 39(5):715-24. [DOI:10.1016/j. ssresearch.2010.06.003]

[36] Whisman MA, Uebelacker LA, Weinstock LM. Psychopathology and marital satisfaction: The importance of evaluating both partners. J Consult Clin Psychol. 2017; 72(5):830-8. [DOI:10.1037/0022-006X.72.5.830] [PMID]

[37] Dadoo P, Dabiri S. Predicting the marital satisfaction based on marital burnout, loneliness and sexual function in married students. J Psychol Sci. 2019; 18(76):499-507. https://www. sid.ir/en/Journal/ViewPaper.aspx?ID=690002

[38] Zarei, Fatemeh (2018). Predicting marital boredom based on family performance and feeling of loneliness in working women in Mehriz [MA. thesis]. Yazd: Yazd University. https://ganj.irandoc.ac.ir/

[39] Yousefi E, Jahangiri P. [Predicting marital boredom based on irrational beliefs and feelings of loneliness in married women (Persian)]. Paper presented at: $1^{\text {st }}$ International Conference on Psychology and Social Sciences. 2 August 2016; Tehran, Iran. https://civilica.com/doc/534582/

[40] Bardoudeh S, Rahenejat AM, Rabiee M, Kianimoghadam AS. [The determination of the relationship between loneliness and internet dependence and marital conflict married couples (Persian)]. J Nurs Phys War. 2018; 16(5):45-31. http:/ /npwjm. ajaums.ac.ir/article-1-459-fa.html

[41] Shakeri J, Hosseini M, Golshani S, Sadeghi K, Fizollahy V. [Assessment of general health, stress coping and marital satisfaction in infertile women undergoing IVF treatment (Persian)]. J Reprod Infertil. 2006; 7(3):269-75. https:/ / www.jri.ir/ article/248 
[42] Karaca A, Unsal G. Psychosocial problems and coping strategies among Turkish Women with infertility. Asian Nurs Res (Korean Soc Nurs Sci). 2015; 9(3):243-50. [DOI:10.1016/j. anr.2015.04.007] [PMID]

[43] Tsapelas I, Aron A, Orbuc T. Marital boredom now predicts less satisfaction 9 years later. Psychol Sci. 2016; 20(5):543-5. [DOI:10.1111/j.1467-9280.2009.02332.x] [PMID]

[44] Pinquart M. Loneliness in married, widowed, divorced, and never-married older adults. J Soc Pers Relat. 2015; 20(1):31-53. [DOI:10.1177/0265407503020001186]

[45] Edelstein RS, Alexander EW, Shaver PR, Schaaf JM, Quas JA, Lovas GS, et al. Adult attachment style and parental responsiveness during a stressful event. Attach Hum Dev. 2017; 6(1):31-52. [DOI:10.1080/146167303100001659584] [PMID]

[46] James S, Huntly J, Hemsworth D. Factor structure of relationship belief inventory. Cog Ther Res. 2002; 26(6):729-55. [DOI:10.1023/A:1021285332295]

[47] Horas D, Cohen-Zrihen A, Ein Dor T, Solomon Z. Stressful life events across the life span and insecure attachment following combat trauma. Clin Soc Work J. 2014; 42(4):375-84 [DOI:10.1007/s10615-014-0477-2]

[48] Lavee Y, Ben-Ari A. Emotional expressiveness and neuroticism: Do they predict marital quality? J Fam Psychol. 2014; 18(4):620-7. [DOI:10.1037/0893-3200.18.4.620] [PMID]

[49] Barton AW. Investigating how external stress does (and does not) impact marital functioning and outcomes: Mechanisms of influence and protective couple processes $[\mathrm{PhD}$. dissertation]. Athens: University of Georgia; 2013. https://esploro.libs.uga.edu/esploro/outputs/doctoral/Investigatinghow-external-stress-does-and/9949332849602959

[50] Aghajani Nouri Z, Fakhri MK, Heidari S. [The relationship between marital boredom, emotional divorce and quality of life in clients referred to counseling centers in Babol (Persian)]. Paper presented at: $5^{\text {th }}$ National Conference on Strategies for Development and Promotion of Educational Sciences and Psychology. 14 September 2017; Tehran, Iran. https:// civilica.com/doc/686891/

[51] Hassankhani M. [The relationship between marital boredom and emotional divorce among working female teachers (Persian)]. Paper presented at: $4^{\text {th }}$ National Conference on Sustainable Development in Educational Sciences and Psychology. 16 June 2016; Tehran, Iran. https:/ / civilica.com/doc/546661/

[52] Khorshidi G, Dasht Bozorgi Z. [Relationship of dark triad of personality, sexual assertiveness and cognitive flexibility with marital burnout in female nurses (Persian)]. Iran J Nurs Res. 2019; 14(1):65-71. http://ijnr.ir/article-1-2167-en.html

[53] Ferreira M, Antunes L, Duarte J, Chaves J. Influence of infertility and fertility adjustment on marital satisfaction. Soc Behav Sci. 2015; 171:96-103. [DOI:10.1016/j.sbspro.2015.01.094]

[54] Malogajski J, Jansen ME, Ouburg S, Ambrosino E, Terwee CB, Morré SA. The attitudes of Dutch fertility specialists towards the addition of genetic testing in screening of tubal factor infertility. Sex Reprod Healthc. 2017; 12:123-7. [DOI:10.1016/j.srhc.2017.04.001] [PMID] 